http://dx.doi.org/10.35381/racji.v5i8.566

\title{
Conciliación en asuntos relacionados con infracciones de tránsito en el Ecuador Vulneración de derechos fundamentales
}

\section{Conciliation in matters related to traffic violations in Ecuador Violation of fundamental rights}

Jaime Alejandro Andrade-Torres

jaime.andrade@ucacue.edu.ec

Universidad Católica de Cuenca, Cuenca

Ecuador

https://orcid.org/0000-0002-6357-340X

Juan Carlos Erazo-Álvarez

jcerazo@ucacue.edu.ec

Universidad Católica de Cuenca, Cuenca

Ecuador

https://orcid.org/0000-0001-6480-2270

Diego Fernando Trelles-Vicuña

dtrelles@ucacue.edu.ec

Universidad Católica de Cuenca, Cuenca

Ecuador

https://orcid.org/0000-0002-8466-7165

Cecilia Ivonne Narváez-Zurita

inarvaez@ucacue.edu.ec

Universidad Católica de Cuenca, Cuenca

Ecuador

https://orcid.org/0000-0002-7437-9880

Recibido: 11 de noviembre de 2019

Aprobado: 13 de diciembre de 2019

\section{RESUMEN}

El objetivo es encontrar y explicar las normas que han sido desconocidas o vulneradas por un acto administrativo, así como sus consecuencias. Para ello se aplica la metodología transversal pues se consideran normas coexistentes en un mismo momento, así como se ha debido acudir a la metodología analítica sintética por cuanto 
ha sido indispensable disgregar los elementos que se ven afectados por una sola disposición y atenderlos a cada uno de ellos de manera particular, acudiendo para ello a la doctrina. Se concluye que la Resolución 327-2014 es inconstitucional pues vulnera la garantía a un debido proceso, el derecho de no autoincriminación, el principio de jerarquía normativa y desconoce el derecho a la seguridad jurídica; por ello se debe establecer la acción de control constitucional correspondiente para que la autoridad competente así lo declare.

Descriptores: Conciliación; debido proceso; Derecho de no autoincriminación; Jerarquía normativa; Jeguridad jurídica.

\begin{abstract}
The objective is to find and explain the norms that have been unknown or violated by an administrative act, as well as its consequences. For this, the transversal methodology is applied because they are considered coexisting norms at the same time, as well as it has been necessary to resort to the synthetic analytical methodology because it has been essential to disaggregate the elements that are affected by a single provision and attend them to each of they in a particular way, turning to the doctrine for this. It is concluded that Resolution 327-2014 is unconstitutional because it violates the guarantee of due process, the right of non-self-discrimination, the principle of normative hierarchy and ignores the right to legal certainty; Therefore, the corresponding constitutional control action must be established for the competent authority to declare it.
\end{abstract}

Descriptors: Conciliation; due process; Right of non-self-discrimination; Normative hierarchy; Legal security.

\title{
INTRODUCCIÓN
}

La autoridad ha sido ejercida por una diversidad innumerable de personajes que han encontrado la fuente de su naturaleza superior en el contexto que entramara la justificación de la jerarquía. Anterior incluso a la comunicación y los lenguajes (como los conocemos ahora), la fuerza física otorgó el rol de autoridad a quien la ostentaba. Con la razón algo más experimentada, pueblos y civilizaciones enteras se postraron a merced de la voluntad de humanos que encarnaron divinidades y entidades fantásticas; épicos episodios de la historia, otrora generoso hontanar de ciencia, experiencia y sabiduría colectiva, primigenia colección de piezas del magnífico universo del 
conocimiento. Con el tiempo la magia perdió terreno en los criterios que determinaban la plataforma del poder, y le siguieron una incontable infinidad de pretextos para su definición, existieron tantas fuentes del poder como modos de ejercerlo (Montesquieu, 1906).

En este devenir de las cosas, la conducta humana ha confirmado la necesidad de ser regulada con fines organizativos (Bobbio, 1991). La evolución ha llevado a establecer estructuras, que determinen, de alguna manera, la forma en la que las personas deben actuar respecto de sus semejantes (Prieto, 2014). Dichas directrices nacen de primitivas nociones de dar a cada quien lo que le corresponde, pues la conciencia va tomando forma, y en los anales de la historia emerge la certeza de que absolutamente todos los actos generan consecuencias.

De lo dicho deriva la formulación de instituciones, competencias, jerarquías y procedimientos, reunidos en normas positivas y obligatorias, dispersas en materias y grados; la fuerza coercitiva del pacto social para el ejercicio de la potestad estatal se constituye y distribuye por medio de la Constitución y se lo ejerce en soberanía (Rousseau, 2003).

El derecho constitucional, no ha escapado del inexorable proceso de evolución de las cosas que del hombre afloran, y como todo, ha debido adaptarse a las condiciones requeridas por cada estadio de la coexistencia humana. Así han visto la luz, corrientes ideológicas que han fundado sus principios en preceptos perfectibles, y han posado su esencia en la organización de los estados, y la administración del derecho, los derechos y la justicia. Ya en nuestro tiempo, hemos visto que el derecho constitucional se ha rendido frente a la corriente de pensamiento dominante de estos días y ésta parte de un mundo repleto de ideas: el neoconstitucionalismo.

Por lo menos de forma amplia, el derecho constitucional actual (neoconstitucionalismo) sustenta su esencia no solo en un catálogo sumamente diverso de fuentes, más allá de eso, ancla su estructura a dos aristas imprescindibles: la primera, que el proceso de 
creación de la norma sea el adecuado, y; segundo, que su contenido sea el desarrollo de los derechos fundamentales, no un atentado contra ellos (Ávila, 2012).

Por otro lado, la Constitución de la República del Ecuador, claramente determina e identifica la facultad normativa, y de manera precisa establece los órganos capaces de ejercerla; esto significa, sin afán de acusación alguna, que la autoridad que se atribuya dicha prerrogativa, sin fundamento en lo establecido por el constituyente en la Carta Magna, no solo estaría cometiendo una ilegalidad, sus actos serían ilegítimos y vulnerarían de manera directa e indiscutible la esencia misma de la Constitución, toda vez que en ella se encuentra (como se deja plenamente establecido en este texto) constituido y distribuido el poder del estado, así como dispuestos los límites en el ejercicio de la autoridad (Rousseau, 2003).

Entonces se plantea como problema que el Consejo de la Judicatura, un órgano de naturaleza puramente administrativa, se inmiscuye y ejerce injerencia directa en el campo jurisdiccional; asume atribuciones privativas del poder legislativo y establece normas adjetivas referidas a los procesos penales de tránsito; vulnera fundamentales derechos contenidos en la Constitución de la República y como consecuencia fáctica, entorpece el flujo de la administración de justicia y soslaya el ejercicio de los principios fundamentales del Derecho Penal (Tamayo Vásquez \& Pino Loza, 2019).

La presente investigación tiene como objetivo dejar de lado la cómoda y ciega obediencia, producto de la cultura conformista a la que nos relega el ejercicio de lo cotidiano; Como en todo, las respuestas emergen cuando se hacen las preguntas correctas; partiendo de éstas: La Resolución 327-2014 del Pleno del Consejo de la Judicatura ¿vulnera la garantía a un debido proceso, el derecho de no autoincriminación, el principio de jerarquía normativa y desconoce el derecho a la seguridad jurídica?, o, dicho de otra forma, ¿Debe una persona renunciar a sus derechos fundamentales para satisfacer una disposición totalmente impertinente? Por supuesto que no, y es por eso que debe accionarse el mecanismo de control 
constitucional correspondiente y de esta forma evitar que normas violatorias de derechos fundamentales continúen formando parte del ordenamiento jurídico.

\section{DESARROLLO}

\section{Control abstracto de constitucionalidad}

La Constitución de la República del Ecuador, determina en su artículo 84 que la Asamblea Nacional, así como toda entidad facultada para emitir normas, tendrá que hacerlo en atención a la adecuación formal y material de las mismas al contenido de la Norma Máxima, a los compromisos internacionales y a todo instrumento que sea imprescindible para garantizar la dignidad al ser humano; de la misma forma la Constitución establece que ninguna reforma del ordenamiento jurídico podrá atentar a los derechos en ella reconocidos (Asamblea Nacional Constituyente, 2008).

Un manejo poco prolijo en el ejercicio de la legislación nacional, así como en la emisión de actos normativos y administrativos ha resultado en la excesiva, dispersa, desordenada y desarticulada formulación de normativa, y ello ha permitido que los entes llamados a velar por la armonía del ordenamiento jurídico tengan serios problemas al ejecutar sus funciones, y ello ha afectado seriamente en la administración de justicia en última instancia, por razones que a primera vista resultan obvias.

Por otro lado, la Corte Constitucional es el organismo con facultad de realizar el control de constitucionalidad sobre normas y actos del poder público que se contrapongan a su contenido y vulneren derechos fundamentales, resultando la declaratoria de inconstitucionalidad en la expulsión del acto o norma del ordenamiento jurídico ecuatoriano (Asamblea Nacional Constituyente, 2008). Dicho esto, se puede afirmar sin temor a equivocarse, que el mecanismo idóneo que debe ser activado para identificar y expulsar disonancias del sistema jurídico, y así garantizar unidad y coherencia del marco normativo es la acción de control abstracto de constitucionalidad (Asamblea Nacional Constituyente, 2008). 
Sobre las bases de las ideas expuestas el Consejo Nacional de la Judicatura es un órgano administrativo de la función pública que regula el funcionamiento de la Función Judicial, y sus competencias se encuentran establecidas en el Código Orgánico de la Función Judicial, sin que en ellas se determine capacidad jurisdiccional alguna, debiendo dirigir su actuar, conforme la norma precipitada, a establecer directrices netamente administrativas y de conducta de los funcionarios judiciales.

El Código Orgánico Administrativo (COA) establece que un acto normativo de carácter administrativo es, en líneas generales, una disposición dada en ejercicio de una competencia otorgada por la ley, cuyos efectos son de naturaleza general y que no se agota con su cumplimiento (Asamblea Nacional del Ecuador, 2017).

En el Registro Oficial Nro. 399 del jueves 18 de diciembre de 2014, se publicó la Resolución No327-2014, en la que el Pleno del Consejo Nacional de la Judicatura resuelve expedir el Reglamento para conciliación en asuntos de infracciones de tránsito, cuya porción resolutiva, que en la especie interesa, a continuación, se menciona: "Art. 7.- La aceptación y pérdida de puntos de la licencia de conducir. - No procede acuerdo conciliatorio sin la aceptación de responsabilidad. En el acta correspondiente se dejará constancia de dicho reconocimiento".

En consideración de la prevalencia del interés público y general sobre el particular, el acuerdo conciliatorio y su cumplimiento no exime a quien haya reconocido el cometimiento de la infracción de tránsito, la pérdida de puntos en la licencia de conducir; para tal efecto, la jueza o juez emitirá la respectiva resolución, sin perjuicio de lo dispuesto en los numerales 3 y 4 del artículo 662 del Código Orgánico Integral Penal. La pérdida de puntos en la licencia de conducir se aplicará de acuerdo a la infracción que motivó la apertura de la fase de investigación previa o instrucción fiscal según corresponda. (Consejo Nacional de la Judicatura, 2014, p. 5)

Se ha dejado establecido que el lus Puniendi (capacidad punitiva del Estado), nace de la necesidad de prohibir ciertas conductas contrarias a la Ley (presupuestos de hecho), a la vez que establece castigos (consecuencias jurídicas) para quien a pesar de ello incurre en aquellas conductas; y en virtud de lo que se menciona, dicho poder adquiere naturaleza obligatoria. Es de entender que el poder punitivo del Estado se encuadra en 
derechos, principios y garantías que enmarcan la acción del ejercicio penal; entre otros, los que se aluden en el presente documento.

Entre las instancias del Consejo de la Judicatura encontramos en su cúspide organizacional al Pleno del Consejo de la Judicatura, al que le compete, entre otras actividades administrativas, relacionadas con la organización, funcionamiento, responsabilidades, control y régimen disciplinario, transparencia y eficiencia de la Función Judicial (Asamblea Nacional del Ecuador, 2009).

Como se ha visto, la resolución 327-2014 del Pleno del Consejo de la Judicatura, establece un procedimiento para dar soluciones alternativas a los conflictos por infracciones de tránsito, y condiciona su consecución a que una de las partes se autoincrimine y a que, a pesar de que se ha dado solución al conflicto y se ha reparado integralmente los derechos lesionados, una de las partes sea sancionada de todas formas con la pérdida de puntos de su licencia de conducir.

Es notable el carácter jurisdiccional de la decisión del Pleno, al limitar la potestad constitucional de los jueces de dar por terminado los conflictos jurídicos con una mínima intervención, al impartir una suerte de venganza estatal sobre los ciudadanos, y al aplicar el derecho penal en primera ratio.

Es evidente que el acto administrativo que motiva el presente estudio, no se apega a los presupuestos establecidos en el artículo 264 del Código Orgánico de la Función Judicial (función del Pleno del Consejo Nacional de la Judicatura); y nos deja un profundo problema a considerar: La Resolución 327-2014 del Pleno del Consejo de la Judicatura ¿vulnera la garantía a un debido proceso, el derecho de no autoincriminación, el principio de jerarquía normativa y desconoce el derecho a la seguridad jurídica?

De lo dicho, es esencial llegar al entendimiento de que una eventual violación de los preceptos contenidos en la pregunta realizada, comprometería de forma grave el efectivo goce y ejercicio de los derechos fundamentales, pues la naturaleza compleja de los derechos aquí invocados debe entenderse de manera particular e independiente, sin 
perjuicio de evidenciar su conexidad, interdependencia y roles compuestos (Carbonell, 2004).

Resulta entonces que la autoridad pública, de manera consciente o no (no corresponde averiguarlo en esta investigación), con un solo acto vulnera derechos particulares y conexos, pilares todos, como queda dicho, del funcionamiento correcto del marco normativo, de la vigencia de la ley y de lo garantizado en la Constitución de la República (Santeliz Contreras, 2016).

\section{Sistema penal inquisitivo y el sistema penal acusatorio - contradictorio}

El caduco sistema penal inquisitivo, consistía en un mecanismo en el cual uno o varios agentes estatales, tenían la obligación de conocer, investigar, juzgar, resolver y ejecutar lo resuelto, en un proceso contra un 'acusado' quien debía enfrentar tal aparataje estatal en evidente desventaja formal y material. Este sistema, a más de representar un claro ejemplo de desequilibrio de derechos y oportunidades, fue un muy apropiado incentivo -dicho de alguna manera- para la realización de prácticas (secretas / no oficiales) de procedimientos extremos (malos tratos y torturas), para conseguir que el 'supuesto' autor de crímenes deleznables reconozca su autoría y de esta manera, el aparato estatal inquisidor (sistema judicial inquisitivo) pueda sancionar en base a una declaración de responsabilidad (prueba plena en aquel sistema) sobre el hecho que se juzga; sin necesidad de actuar prueba alguna que sostenga el contenido de dicha declaración. De ello se obtiene que, la autoincriminación en temas penales olvida el fin primordial del derecho (la justicia), enzarzando la persecución penal pública y la averiguación de la verdad como meta del proceso (Langer, 2001).

Por el contrario, el sistema penal acusatorio / adversarial, que rige en el Ecuador, así lo determina el Código Orgánico Integral Penal (COIP) en su disposición general primera, donde se establece que en lo que no se encuentre previsto en ese código se aplicará el COGEP, en cuánto sea compatible con el procedimiento oral acusatorio penal (Asamblea Nacional del Ecuandor, 2014); ostenta ciertas características imprescindibles 
para su conformación, así lo describe el número 6 del artículo 168 de la Norma Normarum, al exigir en cada proceso, entre otros, el ejercicio del principio de contradicción; y pretende, en estricta armonía con los principios y derechos reconocidos en la Constitución de la República, establecer una plataforma de garantías que protejan a las partes de posibles excesos del poder estatal, así como de una eventual desigualdad de oportunidades entre las partes intervinientes en un proceso, de alguna manera atendiendo a que "el problema de fondo de los derechos humanos no es hoy tanto el de justificarlos como el de protegerlos" (Bobbio, 1991).

Del contenido de los párrafos anteriores, se desprende y evidencia la evolución inexorable de los derechos (Ávila, 2012), en franca armonía con el desarrollo de la sociedad sobre la que rige (Ost, 2017). Entre el cúmulo de 'novedades' que trae el sistema adversarial se encuentra la prohibición de autoincriminación en materia penal, así lo manda la legislación penal ecuatoriana, cuando refiere que el derecho penal se ejercerá en atención a los principios previstos en la ley, entre los que encontramos al que refiere que nadie debe ser obligado a declarar en contra de sí mismo, si la mencionada declaración infiere consecuente responsabilidad penal (Asamblea Nacional del Ecuandor, 2014).

Es notable que en derecho, la ley debe marcar límites perfectamente definidos entre los cuales se desarrollen las actuaciones de los intervinientes dentro de los conflictos jurídicos, esos límites entre otros presupuestos, consisten en, por una parte prohibir procedimientos para la obtención de pruebas, y por otra la prohibición misma de una prueba, caso éste acuñado al término alemán "BEWEISVERBOTE" (Beling, 1903). Que representa la obstrucción necesaria a la utilización de medios probatorios cuya naturaleza se contraponga a la esfera constitucional de protección de los derechos, o que los métodos mediante los cuales se obtienen atenten o vulneren la vigencia de los preceptos constitucionales.

La Constitución de la República del Ecuador, dispone que "...las pruebas obtenidas o actuadas con violación de la Constitución o la ley no tendrán validez alguna y carecerán 
de eficacia probatoria..." (Asamblea Nacional Constituyente, 2008), mientras por otro lado, determina que "... nadie podrá ser forzado a declarar en contra de sí mismo, sobre asuntos que puedan ocasionar su responsabilidad penal..." (Asamblea Nacional Constituyente, 2008). De ello tenemos que la Norma Suprema establece la calidad de "BEWEISVERBOTE" a la prueba obtenida en base a la autoincriminación de un ciudadano, y por tanto es inadmisible para establecer su responsabilidad penal. Así tenemos que "...la pena no es un prius, sino un posterius, no una medida preventiva 0 ante delictum, sino una sanción retributiva o post delictum..." (Ferrajoli, 1995), y, por otro lado, que la sanción penal únicamente puede determinarse previa sentencia basada en el examen y valoración de pruebas legales y legítimas.

\section{Derechos fundamentales vulnerados por la Resolución}

El Debido Proceso ha sido concebido en la evolución del pensamiento jurídico de diversas formas, algunos autores lo entienden como un principio general del derecho (Esparza, 1995), otros como un derecho fundamental (Gómez, 2006); e incluso hay quienes lo definen como una institución (Silva, 2015). La Constitución de la República del Ecuador, establece la naturaleza del debido proceso como un derecho fundamental, sin embargo, debe referirse al mismo como un conjunto no delimitado de derechos y garantías inherentes a las personas, anteriores a todo orden consecutivo y pilar formal y material del estado de derechos y justicia. Al referirse a ello, Cevallos (como se citó en Valdivieso, 2014) expone:

El debido proceso no es una fórmula acabada; sus diversas manifestaciones se orientan siempre a la creación de nuevos matices y nuevas aplicaciones, por lo que su formulación es siempre dependiente de los análisis que sean requeridos y solo la práctica dirá cuáles nuevas orientaciones podrán encontrarse; de tal manera su lista de derivados nunca será taxativa, sino que debe verse a título de ejemplo. Ahí está precisamente el carácter garantista de su existencia. (p. 27)

Es necesario precisar como característica SINE-QUA-NON la obligación ineludible de toda autoridad, en cada materia y grado, de sujetarse a las normas del debido proceso, 
encontrando entonces lo determinado en el Artículo 76 de la Constitución de la República del Ecuador, cuyo primer inciso, en lo fundamental, expresa que en cualquier proceso en el que se determinen derechos, sea cual fuere la naturaleza del trámite, se garantizará el derecho al debido proceso (Asamblea Nacional Constituyente, 2008).

De ello hemos de notar que el debido proceso responde a una naturaleza incierta, no delimitada, pero insoslayable en su aplicación ante cualquier autoridad y en cualquier punto de un proceso en el que se determinen derechos de las personas.

Ahora bien, la Constitución de la República, a más de lo descrito, expone y enumera en el contenido del artículo antes mencionado, las disposiciones que conforman el Debido Proceso, en sentido amplio (El artículo 77 de la Carta Magna establece los elementos constitutivos de manera particular para el debido proceso en el ámbito penal), siendo fundamental, para el objeto de esta investigación, poner especial atención a una de ellas, y que más adelante se trata.

El Artículo 76 de la Constitución de la República establece los criterios que deben regir todos los procesos en los que se determinen derechos de las personas; estos criterios son los márgenes por los que se han de mantener las actuaciones, en los procesos en los que se determinen derechos, para garantizar el debido proceso. El numeral segundo del artículo que se viene mencionando dispone que mientras no exista sentencia de autoridad competente, toda persona mantendrá su estado de inocencia y como tal será tratada (Asamblea Nacional Constituyente, 2008).

Dentro de este marco en una pequeña empresa existen algunos cargos directivos, cuyas disposiciones revisten el mismo grado de autoridad; seguramente esa empresa más temprano que tarde caería en una profunda anarquía y ello, sólo sería el augurio del más rotundo fracaso, puesto que, si bien es cierto, muchas cabezas piensan mejor que una, y lejos de pretender dudas sobre las buenas intenciones de sus miembros, es imprescindible que toda organización, para efectos de gobernabilidad, gobernanza y éxito administrativo, se organice en rangos de jerarquía; con frecuencia se escucha en conversaciones de vereda, se piensa con la cabeza y se camina con los pies. 
No sería posible hablar de orden constituido sin una estructura organizada por disposiciones jerárquicamente distintas (Kelsen, 2009), cuyo orden de prioridad obedezca a una supremacía y sumisión previamente establecida y perfectamente determinada (Pérez, 2014). En el ordenamiento jurídico ecuatoriano, el orden jerárquico de aplicación de las normas es el siguiente:

La Constitución; los tratados y convenios internacionales; las leyes orgánicas; las leyes ordinarias; las normas regionales y las ordenanzas distritales; los decretos y reglamentos; las ordenanzas; los acuerdos y las resoluciones; y los demás actos y decisiones de los poderes públicos ...en caso de conflicto entre normas de distinta jerarquía, la Corte Constitucional, las juezas y jueces, autoridades administrativas y servidoras y servidores públicos, lo resolverán mediante la aplicación de la norma jerárquica superior (Asamblea Nacional Constituyente, 2008).

Sin esta prevalencia jerárquica no sería posible garantizar la integridad del sistema normativo (Espín, 2018), sin embargo, lo manifestado no debe distraer la atención de un punto sumamente trascendente, las disposiciones de un ordenamiento jurídico a más de distinguirse en cuanto a su rango, deben ser armónicas y complementarias entre sí (Prieto, 2014), de ninguna utilidad resultaría que el legislativo o la administración pública generen disposiciones disonantes con otras de carácter superior, o incluso con la Constitución (Hesse, 2012), toda vez que, a más de carecer de eficacia, significarían un atentado contra la seguridad jurídica y demás principios y derechos fundamentales (Trujillo, 2013).

Iniciar un emprendimiento va a requerir compromisos delicados y asumir cierto nivel de riesgo, hay que invertir todo el patrimonio que ha sido logrado luego de muchos años de esfuerzo, sacrificio y trabajo; hay que recurrir a créditos en instituciones financieras, hipotecas, garantías en pólizas de seguros, etc. Sin embargo, el Estado en el que se planea hacerlo carece de estabilidad normativa, es decir, por un lado existe una excesiva legislación respecto de cada ámbito y circunstancia cotidiana, leyes expedidas de manera aleatoria, desordenada y abundante, que además presentan una muy dudosa estabilidad o permanencia en el tiempo. 
Por otro lado, las autoridades administrativas, judiciales, constitucionales, ostentan y ejercen prerrogativas antojadizas, de manera irreverente desconocen las nociones más básicas de reserva de ley. Un estado cuya informalmente escuálida estructura jurídica, ¿prestaría las garantías suficientes para desarrollar sus objetivos? La respuesta es simple: NO. No existe actividad (lícita) que se pueda desarrollar satisfactoriamente en un ambiente de esa naturaleza.

En su evolución, el hombre establece mecanismos para dirigir y limitar el comportamiento de la sociedad, desestimando la necesidad de atender el desmedido e ilimitado poder y atribuciones de quienes dirigían los estados, dando paso a atroces aberraciones de gobernantes y autoridades a lo largo de la historia; un escenario en el que se crean normas a conveniencia y beneficio del gobernante, de acuerdo a las circunstancias y al panorama coyuntural, normas que la autoridad cumplía o no, según las reglas del antojo (López, 2011); condiciones que, sin embargo, sirvieron de inspiración para la estructuración de procedimientos y normas que rijan por sobre cualquiera; que sin importar las circunstancias, sometan a su imperio a cualquiera que ostente autoridad, y que dirijan el curso del poder mismo de un estado.

El estado de derecho es aquel que tiene claras y determinadas las reglas del juego, las que son de carácter estrictamente procedimental y que deben ser respetadas por todas las instituciones del poder público, además de regir las relaciones de estas últimas con los ciudadanos, en otras palabras, es un estado en el que los poderes están sujetos a la ley (Carbonell, 2004).

Es de entender que el poder del estado se encuadra en derechos, principios, garantías y la compleja articulación de instituciones, las que deben ser perfectamente definidas y delimitadas, de contenidos claros, explícitos, comprensibles y coherentes; es por ello que en este documento nos referimos al principio de seguridad jurídica. La seguridad jurídica es la institución que impide que las actividades humanas se realicen sobre una superficie pantanosa, turbia e inconsistente; y en su defecto, plantea una estructura fuerte con plataformas sólidas para establecer una sociedad y sus determinantes, se 
presenta como el eslabón más fuerte de una democracia que se ha formado a través del tiempo gracias a la constante lucha de los pueblos por encontrar el respeto al derecho mismo, por medio de la ley (López, 2011).

Una definición amplia pero acertada es en la que López (2011) sugiere que "la Seguridad Jurídica es un principio conocido en el área del derecho, que representa la certeza del conocimiento de todo lo previsto como prohibido, mandado y permitido por el denominado poder público". La seguridad jurídica establece criterios ineludibles y permanentes para su real vigencia, mismos que sin un orden premeditado se exponen y son: la sujeción de los poderes públicos al derecho (Carbonell, 2004); la Constitución como medio para controlar el poder (Rousseau, 2003); división e independencia de los poderes (funciones) del Estado, Límite de las atribuciones de la Autoridad (Montesquieu, 1906).

No se puede pasar por alto la irrefutable necesidad de positivar las normas como cimiento de la seguridad jurídica (Forero, 2006), así como establecer un sistema y procedimiento claro previo y regular para la modificación de las mismas, pues "una clara manifestación de la seguridad jurídica es la ley escrita, debidamente dada a publicidad para conocimiento de todo el pueblo. La ley formalmente sancionada, siempre ha sido objeto de respeto y obediencia, máxime en los regímenes democráticos donde se expresa la voluntad popular" (Urbano, 2007). En el mismo sentido, "la seguridad jurídica implica una calidad de la norma jurídica, que se conecta con factores relativos a la creación, promulgación y contenido de la regla jurídica" (Rodríguez y Bravo, 1997), es decir que la norma debe presentar suficientes características formales que garanticen su estabilidad, aunque sea de manera relativa.

En esta perspectiva, en el presente apartado no se pretende determinar las incongruencias e incoherencias del ordenamiento jurídico que nos rige; entendiéndolo de manera apropiada, es un acercamiento a la naturaleza misma de la seguridad jurídica, como plataforma idónea para el asentamiento de cualquier sociedad, sea cual fuere su estructura económica, política o social; en todo caso, la pretensión surge de la 
idea de exponer sus dimensiones y establecer el grave riesgo que corre por la exposición constante a factores formales y sustanciales que merodean la cotidianeidad de los ordenamientos jurídicos, como son la falta de claridad y oportunidad en la creación de las leyes; falta de reserva de la ley; y el desconocimiento de la ley por parte de quien no ha sido formado en ciencias jurídicas (Carbonell, 2004).

Por otro lado, es necesario entender las dimensiones de la seguridad jurídica, al menos en su sentido más amplio: la previsibilidad de las acciones y sus consecuencias jurídicas, y el funcionamiento de los poderes públicos (Carbonell, 2004), conocidas también como corrección estructural y corrección funcional (Perez, 2000). El poder no puede ni debe ser utilizado por la administración de manera desmedida e ilimitada, pues de ello, por un lado, desencadenaría un conflicto de competencias, y por otro, detonaría la debacle insostenible de las relaciones jurídicas, instituciones y el derecho mismo.

El artículo 226 de la Constitución de la República, determina el principio de competencia, y lo articula íntimamente con la legalidad, la seguridad jurídica y la jerarquía normativa, al establecer de manera determinante que la función pública únicamente ejecutará las competencias establecidas en la normativa vigente (Asamblea Nacional Constituyente, 2008).

El artículo 82 de la misma Norma Máxima del ordenamiento jurídico ecuatoriano, establece de manera determinante que "...el derecho a la seguridad jurídica se fundamenta en el respeto a la Constitución y en la existencia de normas jurídicas previas, claras, públicas y aplicadas por las autoridades competentes." (Asamblea Nacional Constituyente, 2008). Es evidente que, de lo dicho, el constituyente establece un candado que limita el uso desmedido del poder y evita con ello el abuso y la arbitrariedad en el ejercicio de sus funciones.

De igual manera es clara y legítima la obligación irrestricta que tienen las autoridades y personeros de la función pública de apegarse al contenido de la Constitución de la República, hacer efectivo el respeto a los principios y derechos en ella establecidos; así como dirigir sus actuaciones dentro de los márgenes dispuestos por la Ley, pues la 
existencia de normas jurídicas previas, claras y públicas, garantiza la certeza en las actuaciones de quienes se ven sujetos a la autoridad.

Luego de haber establecido de manera muy breve y sucinta el contexto necesario, producto de un acto administrativo cuya naturaleza resulta extremadamente confusa, Con afán netamente explicativo, y que ayudará a dilucidar los conceptos aquí vertidos de una forma ilustrativa, se presenta la solución a la violación de derechos fundamentales en la figura siguiente:

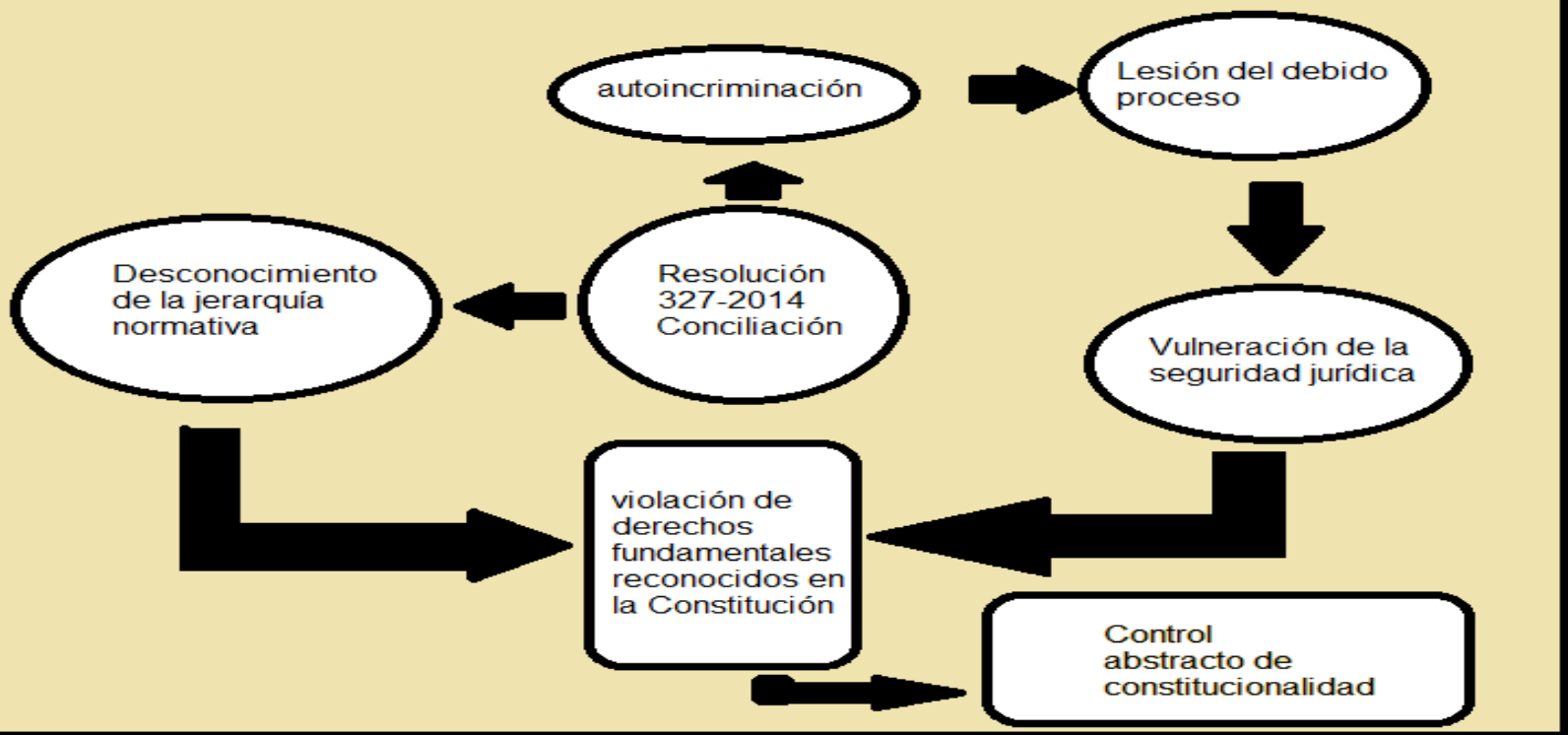

Figura 1. Derechos interdependientes e independientes vulnerados por la Resolución 327-2014 del Pleno del Consejo Nacional de la Judicatura.

\section{METODOLOGÍA}

La presente investigación parte de la metodología analítica sintética, toda vez que se ha requerido realizar profundas reflexiones sobre bases establecidas en estudios doctrinarios, así como el alcance de normas relacionadas con la problemática de este trabajo, ubicando sus puntos de conexión con la Resolución aludida, y entablando un contexto de síntesis en función de los valores particulares que se han obtenido del alcance mismo de las normas y textos doctrinarios. Del mismo modo, se ha empleado la 
metodología temporal transversal, pues de lo encontrado se ha determinado que los objetos de esta investigación son fuentes de derecho y normas que coexisten en un mismo plano temporal, sin que se haya requerido de manera imprescindible plantear contextos históricos o proyecciones futuras para alcanzar los objetivos de este estudio (Argudo, Erazo y Narváez, 2019).

\section{APORTES}

La Resolución N 327-2014 del Pleno del Consejo Nacional de la Judicatura, violenta (entre otros) fundamentalmente los derechos y principios abordados en el presente trabajo, y así lo resaltamos a continuación:

En primer momento se condiciona el acceso a un procedimiento legítimo a la autoincriminación del ciudadano, obligándolo a declarar en contra de sí mismo, precepto claramente prohibido en el número 8 del artículo 5 del COIP, donde categóricamente existe prohibición expresa al respecto.

Sin derecho a la defensa ni valoración de prueba alguna (nos referimos a la valoración de prueba legítima, y no a la autoincriminación previamente denunciada) se declara la culpabilidad de un ciudadano, violando completamente el derecho al debido proceso, prescrito y desarrollado en el artículo 76 de la Constitución de la República del Ecuador, así como determinado en el primer artículo del Código Orgánico Integral Penal.

De manera totalmente injustificada, se debela el desconocimiento al principio de jerarquía normativa contenido en el artículo 425 de la Carta Magna, al permitirse el Pleno del Consejo de la Judicatura expedir disposiciones que se sobreponen a la legislación penal vigente, a la Constitución de la República, a la más ligera noción de derecho, y a un muy básico ejercicio de sentido común, destruyendo en consecuencia, cualquier vestigio de seguridad jurídica, desapareciendo su concepto de nuestro ordenamiento jurídico.

Concluyo este trabajo con una corta reflexión: una disposición violatoria de principios y derechos constitucionales, contraria a la ley, al derecho, injusta en extremo, ¿debe ser 
obedecida? NO. Sin embargo, es preciso dar trámite al procedimiento constitucional correspondiente (acción de control abstracto de constitucionalidad), determinado en el artículo 74 y siguientes de la Ley Orgánica de Garantías Jurisdiccionales y Control Constitucional, y de esta manera conseguir su expulsión definitiva del ordenamiento jurídico vigente en el país.

\section{REFERENCIAS CONSULTADAS}

1. Argudo Tello, K. J., Erazo Álvarez, J. C., \& Narváez Zurita, C. I. (2019). Evaluación de Control Interno en Riesgos Estratégicos para la Dirección de Planificación de la Universidad de Cuenca. Koinonía, 75.

2. Asamblea Nacional Constituyente. (20 de Octubre de 2008). Constitución de la República del Ecuador. Derechos de protección, 1-80. Quito, Pichincha, Ecuador: Registro Oficial.

3. Asamblea Nacional del Ecuador. (2009). Código Orgánico de la Función Judicial. Quito: Registro Oficial.

4. Asamblea Nacional del Ecuador. (2017). Código Orgánico Administrativo. Quito: Registro Oficial.

5. Asamblea Nacional del Ecuandor. (2014). Código Orgánico Integral Penal. Quito: Registro Oficial.

6. Ávila Santamaría, R. (2012). Los derechos y sus garantías. Ensayos críticos. Quito: Centro de estudios y difusión de derecho constitucional.

7. Beling, E. V. (1903 (reimpresión 1968)). Die Beweisverbote als Grenzen der Wahrheitserforschung im Strafproze. Minnesota: Wissenschaftliche Buchgesellschaft.

8. Bobbio, N. (1991). El tiempo de los derechos. En N. Bobbio, El tiempo de los derechos (pág. 61). Madrid: Sistema.

9. Carbonell, M. (2004). Los Derechos Fundamentales en México. Mexico: UNAM.

10. Carbonell, M. (2004). Los Derechos Fundamentales en México. México: UNAM.

11. Consejo Nacional de la Judicatura. (2014). Resolución N³27-2014. Registro Oficial Nro.399, 5.

12. Constitución de la República del Ecuador, Art. 225. 
13. Constituyente, A. (20 de Octubre de 2008). Constitución de la República del Ecuador. Registro Oficial, págs. 1-80.

14. Esparza Leibar, I. (1995). El Principio del proceso debido. Madrid: Editor J.M. Bosch.

15. Espín, E. (2018). Manuales de derecho constitucional. En E. E. Luis López Guerra, Manuales de derecho constitucional (Onceava ed., págs. 58-61). Valencia: Tirant lo Blanch.

16. Ferrajoli, L. (1995). Derecho y Razón. Madrid: Trotta.

17. Forero Ramírez, J. C. (2006). Aproximación al principio de oportunidad. Bogotá: Grupo Editorial Ibañez.

18. Gómez Lara, C. (2006). El debido proceso como derecho humano. Mexico: Instituto de Investigaciones Jurídicas de la Universidad Nacional Autónoma de México.

19. Hesse, K. (2012). Escritos de derecho constitucional. Madrid: Marcial Pons.

20. Kelsen, H. (2009). Teoría pura del derecho (Cuarta (novena reimpresión) ed.). Buenos Aires: Editorial Universitaria de Buenos Aires.

21. Langer, M. (2001). La dicotomía acusatorio - inquisitivo y la importación de mecanismos procesales de la tradición jurídica anglosajona. Algunas reflexiones a partir del procedimiento abreviado. En J. B. Bovino, El procedimiento abreviado (págs. 106-107). Buenos Aires: Editores del Puerto.

22. Langer, M. (2001). La dicotomía acusatorio - inquisitivo y la importación de mecanismos procesales de la tradición jurídica anglosajona. Algunas reflexiones a partir del procedimiento abreviado. En J. B. Bovino, El procedimiento abreviado (págs. 97-133). Buenos Aires: Editores del Puerto.

23. López Oliva, J. O. (2011). LA CONSAGRACIÓN DEL PRINCIPIO DE SEGURIDAD JURÍDICA COMO CONSECUENCIA DE LA REVOLUCIÓN FRANCESA DE 1789. Revista Prolegómenos - Derechos y Valores, 121-134.

24. Montesquieu, C. L. (1906). El espíritu de las leyes. Madrid: Librería General de Victoriano Suárez.

25. Ost, F. (2017). ¿Para qué sirve el Derecho?... para contar hasta tres. Alicante: Marcial Pons. 
26. Perez Luño, A. E. (2000). Seguridad Jurídica. Una Garantía del Derecho y la Justicia. Madrid: Trotta.

27. Pérez Royo, J. (2014). Curso de derecho constitucional (Decimocuarta ed.). Madrid: Marcial Pons.

28. Prieto Sanchis, L. (2014). Apuntes de teoría del derecho. Madrid: Trotta.

29. Rodríguez-Piñero y Bravo-Ferrer, M. (1997). Constitución, Legalidad y Seguridad Jurídica. Anuario de la Facultad de Derecho de la Universidad Autónoma de Madrid, 157-178.

30. Rousseau, J.-J. (2003). EL CONTRATO SOCIAL. Buenos Aires: La Página.

31.Santeliz Contreras, M. (2016). Mediatio et Conciliatio: Medios alternos de solución de conflictos inmersos en la legislación laboral de Venezuela. IUSTITIA SOCIALIS, $1(1), \quad 31-48 . \quad$ Recuperado de https://fundacionkoinonia.com.ve/ojs/index.php/lustitia Socialis/article/view/80/66

32. Silva Castro, A. (2015). El debido proceso. Mexico: Porrua.

33. Tamayo Vásquez, F., \& Pino Loza, E. (2019). Derechos Humanos de los niños, niñas y adolescentes en los procesos Arbitrales. IUSTITIA SOCIALIS, 4(7), 97114. doi:http://dx.doi.org/10.35381/racji.v4i7.357

34. Trujillo, J. C. (2013). Constitucionalismo contemporáneo. Teoría, procesos, procedimientos y retos. Quito: Universidad Andina Simón Bolívar / Corporación Editora Nacional.

35. Urbano Salerno , M. (2007). Calidad Institucional y Seguridad Jurídica. Academia Nacional de Ciencias de Buenos Aires, 453.

36. Valdivieso, S. (2014). Litigación Penal en el Ecuador. Cuenca: Librería y Editorial Jurídica Carrión.

37.Zagrebelzky, G. (s.f.). El derecho ductil. Obra citada.

(C2020 por los autores. Este artículo es de acceso abierto y distribuido según los términos y condiciones de la licencia Creative Commons Atribución-NoComercial-Compartirlgual 4.0 Internacional (CC BY-NC-SA 4.0)

(https://creativecommons.org/licenses/by-nc-sa/4.0/). 